\title{
CORRECTION
}

W) Check for updates

Cite this: J. Mater. Chem. A, 2017, 5, 10722

DOI: $10.1039 / \mathrm{c} 7 \operatorname{ta9} 9099 f$

www.rsc.org/MaterialsA

\section{Correction: From anisotropic graphene aerogels to electron- and photo-driven phase change composites}

\author{
Guangyong $\mathrm{Li}^{\text {ab }}$ Xuetong Zhang, ${ }^{\text {*a }}$ Jin Wang ${ }^{\mathrm{a}}$ and Jianhui Fang*b
}

Correction for 'From anisotropic graphene aerogels to electron- and photo-driven phase change composites' by Guangyong Li et al., J. Mater. Chem. A, 2016, 4, 17042-17049.

The authors would like to add a conference proceedings paper (ref. 1 below) to the reference list of this article, in order to give readers a better understanding of the background of the work reported in the article.

The Royal Society of Chemistry apologises for these errors and any consequent inconvenience to authors and readers.

\section{References}

1 Y.A. Samad, Y. Li, K. Al-Tamimi, R. A. Marar, S. M. Alhassan and K. Liao, Voltage and Photo Driven Energy Storage in Graphene Based Phase Change Composite Material, in ICREGA'14 - Renewable Energy: Generation and Applications, ed. M. Hamdan, H. Hejase, H. Noura and A. Fardoun, Springer Proceedings in Energy, Springer, Cham, 2014. 